\title{
REVISIONES
}

\section{Diarios de bicicleta: procesos educativos vivenciados en la Ruta de las Emociones}

\author{
Bicycle diaries: educational processes in the Emotions Route
}

Diários de bicicletas: processos educativos vivenciados na Rota das Emoções

\author{
Luiz Gonçalves-Junior ${ }^{1}$, Denise Aparecida Corrêa ${ }^{2}$, \\ Clayton da Silva Carmo ${ }^{3}$, Sergio Toro Arévalo ${ }^{4}$
}

\author{
${ }^{1}$ Departamento de Educação Física e Motricidade Humana (DEFMH), Universidade Federal de São Carlos \\ (UFSCar); Sociedade de Pesquisa Qualitativa em Motricidade Humana (SPQMH), \\ luiz@ufscar.br \\ ${ }^{2}$ Departamento de Educação Física da Universidade Estadual Paulista Júlio de Mesquita Filho (DEF-UNESP/ \\ Bauru); Núcleo de Estudos de Fenomenologia em Educação Física (NEFEF/UFSCar); SPQMH, \\ decorrea@fc.unesp.br \\ ${ }^{3}$ Secretaria da Educação do Estado de São Paulo (SEE-SP); SPQMH; NEFEF/UFSCar, \\ spina002@gmail.com \\ ${ }^{4}$ Instituto de Ciencias de la Educación, Universidad Austral de Chile; SPQMH; NEFEF/UFSCar, \\ seatoro@gmail.com
}

\section{RESUMEN}

Este estudio tuvo como objetivo identificar y analizar los procesos educativos vivenciados por un grupo de cicloturistas del "Proyecto de Educación Ambiental y Ocio", durante un cicloviaje. Sobre la base del análisis cualitativo de los registros sistemáticos realizados en diarios de campo emergieron las siguientes categorías: Conocimientos Técnicos Específicos; Ciclo-Empatía; Negociación y Fenomenología del Entorno. El análisis permitió identificar procesos educativos relacionados al conocimiento técnico sobre el uso de la bicicleta y de aspectos geográficos. Los datos revelaron que la apertura a la que se expone el cicloturista provocaron actitudes empáticas entre el grupo y las personas que habitan las localidades recorridas y una vivencia más profunda del medio ambiente. Se concluye que la utilización de la bicicleta puede favorecer acciones educativas orientadas hacia la promoción del ocio crítico y de la educación ambiental.

Palabras clave: procesos educativos, cicloturismo, ocio, educación ambiental.

\section{ABSTRACT}

The objective of the research was to identify and analyze educational processes experienced by a group of cyclotourists participating in the "Environmental Education and Leisure Project," during a cyclotrip. Based on records in field diaries and qualitative analysis, the following categories emerged: Specific Technical Knowledge; Cycle-Empathy; Negotiation; Environmental Phenomenology. Categories allow the recognizion of various educational processes related to technical expertise on bicycle use, as well as some geographical aspects, many of which were possible only from the knowledge of local communities. Data show that the openness exposed by the cyclotourist also triggered empathic attitudes among group members and the people who inhabited the places covered, experiencing nature in depth. We consider the use of bicycles as encouragement for educational activities aimed at promoting critical experience of leisure and environmental education.

Keywords: educative processes, cyclotrip, leisure, environmental education. 


\section{RESUMO}

O objetivo da pesquisa foi identificar e analisar os processos educativos vivenciados por um grupo de cicloturistas do "Projeto de Educação Ambiental e Lazer", durante uma cicloviagem. Baseado na análise qualitativa destes emergiram as seguintes categorias: Conhecimentos Técnicos Específicos; Ciclo-Empatia; Negociação; Fenomenologia do Entorno. Nas categorias observamos diversos processos educativos relacionados a conhecimentos técnicos no uso da bicicleta, de aspectos geográficos para o deslocamento, muitos dos quais foram possíveis apenas a partir do saber das comunidades locais. As situações de abertura a que se expõe o cicloturista também destacaram-se, pois desencadearam atitudes empáticas entre os membros do grupo e entre eles e as pessoas que habitavam os locais percorridos, assim também possibilitou uma experiência sensível ao ambiente. Consideramos o uso da bicicleta como atividade potencializadora de ações educativas com vistas à promoção da vivência crítica do lazer e da educação ambiental.

Palavras-chave: Processos Educativos. Cicloturismo. Lazer. Educação Ambiental.

\section{INTRODUCCIÓN}

Esta investigación tiene como base principal el seguimiento y estudio del "Projeto de Educação Ambiental e Lazer" (PEDAL)1, particularmente, en su penúltimo cicloviaje realizado en enero del 2013 por el noreste brasilero, en la denominada "Ruta de las Emociones", que comprende el trayecto litoral de Fortaleza/Ceará a San Luís/Maranhão, pasando, también, por el litoral de Piauí.

PEDAL, como proyecto, surgió el año 2008, a partir del interés común, entre amigos/ as de docentes de educación física y otras áreas, en viajar por lugares de paisajes no urbanos que favoreciesen el contacto con senderos, bosques, ríos, cascadas, lagos, represas, playas, plazas, parques, museos, haciendas históricas, unidades de conservación, centros de educación ambiental, entre otros, buscando una alternativa de vivencias desvinculadas del ocio de consumo. A esto se sumaba, además, la preocupación ambiental.

El devenir del grupo (compuesto por 20 personas en su mayor parte profesores/as de Educación Básica o Superior y estudiantes de pregrado, además de un gastrónomo, nutricionista y secretaria) implicó pasar de un origen fundamentalmente vinculado a la práctica del ocio, hacia una visión académica, ampliándose la atención hacia estudios socioculturales del ocio, la educación ambiental, la preparación/entrenamiento/ alimentación. Esto derivó en la posibilidad de divulgar la experiencia y los estudios en revistas, congresos y, junto a estudiantes de Educación Básica y Superior, desarrollar el proyecto social de extensión universitaria "PEDAL-Consciente"”.

El uso de la bicicleta es referenciado por el término ciclismo y este, de acuerdo con la forma e intencionalidad de utilización, se diferencia a lo menos en tres tipos: transporte, deporte y ocio. Este último se caracteriza por la ausencia del elemento competitivo, e incluye el ciclismo de larga distancia, el ciclismo recreativo y el cicloturismo (Roldan, 2000).

\footnotetext{
Para saber mas sobre PEDAL: link del grupo de cicloturismo http://www.ufscar.br/ defmh/spqmh/pedal.html; blog del grupo de cicloturismo http://pedaldafederal.blogspot.com.br/; blog del proyecto social de extensión universitária "PEDALConsciente", incluyendo adolescentes de escuelas públicas de la ciudad de São Carlos, desarrollado en la Universidad Federal de São Carlos http://pedalconsciente.blogspot.com.br/

2 "El proyecto utiliza el ciclismo como opción de vida saludable y sustentable, observando el uso de la bicicleta en el contexto de ocio, recreación, deportivo y de transporte. La implementación se efectúa en cuatro módulos: Medio Ambiente y Ciclismo en la Tierra; Mobilidad Urbana; Mecánica Básica de la Bicicleta; Escuelita de Ciclismo y Salud. La propuesta es incentivar el uso de la bicicleta como transporte, de manera adecuada, respetando las Leyes de Tránsito; conscientizar sobre el papel del ser humano en el medio ambiente; incluir a los adolescentes en actividades de recreación y promoción de salud; y promover la convivencia social entre los adolescentes" (Gonçalves Junior, 2014).
} 
Las experiencias abordadas en este estudio corresponden a esta última vertiente, es decir, el cicloturismo entendido como:

[...] todo tipo de viaje, de un día o más de duración, que tenga como objetivo conocer lugares y practicar turismo utilizando la bicicleta como medio de locomoción, diferenciándose de otras actividades no competitivas por sus mayores dimensiones espaciales, cronológicas y su planificación previa (Roldan, 2000: 14).

En Brasil el cicloturismo es un fenómeno emergente y por esto son pocas las informaciones, investigaciones y bibliografía dedicadas a tal temática, aunque, la creciente expansión de la citada práctica puede ser percibida en el aumento de número de participantes, de relatos de viajes y libros (Byrne, 2010), y en Internet, de reportajes, también como en el surgimiento de trabajos académicos sobre el tema (Schetino, 2006).

Dado el reciente contexto de expansión del cicloturismo en Brasil, Schetino (2005) contribuye con otros elementos para la conceptualización de esta práctica, planteando que:

(...) cualquier viaje o paseo turístico en el cual se utilice la bicicleta como medio de transporte. Esta definición contempla no sólo los grandes viajes solitarios o en grupos contados en libros y relatos, sino también la nueva y creciente demanda del mercado, de la utilización de bicicletas en pequeños paseos y rutas turísticas. En este sentido, la tenue línea que diferencia el cicloturismo de un paseo en bicicleta es exactamente el concepto de turismo, que lleva en consideración factores como estar fuera de su residencia habitual, tomar contacto con lo nuevo, conocer nuevos lugares y culturas (Schetino, 2005: 192).

Esta definición más amplia nos permite entender como cicloturista tanto a aquellas personas que efectúan viajes extensos en vacaciones, fines de semana o feriados, como también a aquellas que utilizan la bicicleta en pequeñas rutas, e inclusive las que, llevando sus bicicletas, se ubican en localidades específicas para, a partir de allí, realizar trayectos por el entorno para conocer puntos turísticos de una determinada región. En ese sentido, Duarte (2008) en su estudio presenta distinciones entre "cicloturistas de ruta", que recorren grandes rutas hospedándose en diversos puntos, y "cicloturistas de senderos", que se establecen en un lugar y salen en bicicleta cubriendo senderos locales y cercanos.

Asumiendo estas observaciones, entendemos los paseos y viajes del PEDAL como prácticas de cicloturismo, pues lo que compromete al grupo no es la preocupación por la performance, tampoco por el tiempo y distancias recorridas, sino los nuevos paisajes, lugares, personas y culturas con las cuales tomar contacto, así como la sensación de libertad y placer que provocan los trayectos, ya sea paseos cortos de un día, o viajes prolongados de varios días o semanas, implicando estudiar previa y pormenorizadamente rutas y puntos de parada para alimentación y descanso.

Los primeros trayectos realizados por el grupo PEDAL fueron cortos, restringidos a senderos posibles de cubrir en un día en la región de residencia, estudio o trabajo de la mayoría de los participantes (San Carlos, al interior de San Paulo), tales como: el circuito histórico de las haciendas de la región (Hacienda Valle del Quilombo, Hacienda Santa Maria, Hacienda Conde del Pinhal); las ciudades (Araraquara, Ibaté y Itirapina) y distritos cercanos (Santa Eudóxia y Água Vermelha). Tales paseos, mas allá de fines turísticos y de agenciamiento del ocio, también posibilitaron la preparación para trayectos más largos, y lentamente el grupo fue trazando objetivos más ambiciosos al punto de proponerse viajes de días y semanas. 
De tal forma, en enero de 2009 el grupo realizó su primer cicloviaje, entre San Carlos y el municipio balneario de Águas da Prata (São Paulo) y, desde esa experiencia, pasó a organizar y realizar cicloviajes anualmente ${ }^{3}$, normalmente en el mes de enero, período de vacaciones de los/as participantes. PEDAL posee un registro histórico de aproximadamente 3.600 kilómetros recorridos en un total de seis cicloviajes, siendo el más reciente aquel realizado el 2014 entre Uruguay y Argentina. Siendo objeto de este estudio el $5^{\circ}$ cicloviaje, denominado "Ruta de las Emociones", que tuvo lugar, en enero de 2013, por la región litoral de tres estados de la República Federal de Brasil: Ceará, Piauí e Maranhão.

Destacamos que a nuestro entender, la práctica del cicloturismo se sustenta en la Ciencia de la Motricidad Humana, que según Sérgio (1999) se expresa como "el movimiento intencional de transcendencia, es decir, el movimiento de significación más profunda", en el que lo esencial "es la experiencia originaria, donde emerge también la historia de la corporeidad del sujeto, dado que no hay experiencia vivida sin la intersubjetividad que la praxis supone. El ser humano es todo motricidad, en una continua apertura a la realidad más radical de la vida" (Sérgio, 1999: 17-18).

Más específicamente, y en el contexto del cicloturismo, nos situamos en lo que se ha denominado ecomotricidad (Rodrigues y Gonçalves Junior, 2009; Toro y Lührs, 2012), vale decir: prácticas "desarrolladas con intencionalidad" específica hacia procesos educativos de reconocimiento de las relaciones ser humano-medio ambiente, basándose en la sinergia entre educación ambiental, motricidad humana y pedagogía dialógica" (Rodrigues y Gonçalves Junior, 2009: 988).

Según Rodrigues y Gonçalves Junior (2009):

[...] la búsqueda de esta sinergia se genera a partir de dos puntos primordiales: la crisis ambiental contemporánea y la concepción del cuerpo en el mundo. La carencia de estudios sobre esas sinergias justifica su interés, entendiéndose la relevancia científica (escasa en la literatura) y social (ética ambiental) de esas posibles relaciones (Rodrigues y Gonçalves Junior, 2009: 988).

El objetivo central de esta investigación es identificar y analizar los procesos educativos vivenciados por un grupo de cicloturistas en el contexto del cicloviaje. Entendemos que los procesos educativos ocurren en una relación mutua de aprendizaje y no sólo en una situación en que uno enseña a otro, teniendo como presupuesto fundamental para su desarrollo el diálogo equitativo y la intencionalidad dirigida hacia la cooperación, la superación, el ser más, demandando autonomía, posibilidad de decisión y de transformación. Tales condiciones permiten a los involucrados comprender en contexto, valores y códigos del grupo, de la comunidad y de la sociedad en que viven, teniendo la posibilidad de reflexionar críticamente sobre su propia condición de pertenencia al mundo con los otros, educándose, y personalizándose. ${ }^{5}$

$1^{\circ}$ Ruta/2009: "Ruta das Águas Paulistas": São Carlos (São Paulo) - Águas da Prata (São Paulo) 300Km - 10 días. $2^{\circ}$ Ruta/2010: "Ruta Sudeste": São Carlos (São Paulo) - Paraty (Rio de Janeiro) 650Km - 14 días. $3^{\circ}$ Ruta/2011: "Ruta São Carlos - Ilha Grande": São Carlos (São Paulo) - Ilha Grande (Rio de Janeiro) 750Km - 15 días. 4 Ruta/2012: "Ruta da Canastra": São Carlos (São Paulo) - Região da Serra da Canastra (Minas Gerais) 500Km - 13 dias. $5^{\circ}$ Ruta/2013: "Ruta das Emoções": Ceará - Piauí - Maranhão 650km - 20 días ( objeto de este articulo). $6^{\circ}$ Ruta/2014: "Ruta Uruguay - Argentina": Montevideo (Uruguay) - Buenos Aires (Argentina) $\sim 650 \mathrm{Km}-23$ días (primer cicloviaje internacional del grupo).

Comportamiento corpóreo-mundano y existencial, en el cual se constituye y reconstituye el mundo significado (Fiori, 1986).

Para mayor profundidad sugerimos la lectura de Oliveira et al (2009); Brandão (2002); Freire (2005a; 2005b). 
Además, explicitamos que la denominada "Ruta de las Emociones" es un trayecto turístico que emerge como resultado del Proyecto de la Red de Cooperación Técnica para la Implementación de Rutas, implementado por Servicio Brasilero de Apoyo a las Micro y Pequeñas Empresas (SEBRAE) y el Ministerio de Turismo, que, desde el 2005, trabaja en conjunto con líderes locales, emprendedores y entidades, para promover el desarrollo de la región, entendiendo el potencial turístico como posibilidad de desarrollo sustentable de las comunidades (Rota das Emoções, 2013).

La nomenclatura de la ruta alude a las emociones proporcionadas por las prácticas (trekking, surf, windsurf, kitesurf, senderos off road, etc.) ligadas al turismo de aventura y al ecoturismo, pues el trayecto abarca como puntos centrales el Parque Nacional de las Sabanas Maranhenses (MA), el Área de Protección Ambiental del Delta de Parnaíba (PI) y el Parque Nacional de Jericoacoara (CE) (Rota das Emoções, 2013).

Luego de la presentación de algunas propuestas, entre las que se encontraba la de la "Ruta de las Emociones", la elección de este trayecto se hizo de manera colectiva. A partir de la decisión, el grupo realizó indagaciones sobre la viabilidad del viaje en bicicleta, descubriendo, por medio de relatos de otros practicantes de cicloturismo en internet, diversas posibilidades de trayectos y que su realización en el sentido Fortaleza-São Luís era favorecida por la dirección este-oeste del viento en la región, aspecto central para el ahorro energético y avance del ciclista. En consecuencia, se eligió dicha ruta.

El período de viaje fue decidido de común acuerdo, buscando conciliar el período de vacaciones de todas y todos. El viaje duró 20 días, específicamente entre 02/01/2013 y 21/01/2013, incluyendo los días de desplazamiento en avión desde San Paulo a Fortaleza (ida) y de San Luis a San Paulo (regreso). El cicloviaje en cuestión tuvo, por tanto, una característica hibrida debido al uso de otros transportes en función del tiempo disponible y de las características del terreno. También fueron utilizados: bus, transporte $4 \mathrm{x} 4 \mathrm{y}$ balsas para la travesía de ríos.

El grupo en cicloviaje se constituyó de 8 personas, 4 hombres y 4 mujeres, con edades de entre 27 y 50 años, profesores/as de educación básica y de enseñanza superior, estudiantes de post-grado, una nutricionista y una secretaria.

\section{PROCEDIMIENTOS METODOLÓGICOS}

Se trata de una investigación de campo que incluyó como procedimiento básico de colecta de datos el registro sistemático de notas en diarios de campo. Estos, según Bogdan y Biklen (1994), son como un relato escrito de aquello que el investigador percibe durante el proceso de la propia recolección y de la reflexión sobre los datos de un estudio cualitativo.

Los mismos autores señalan que los aspectos descriptivos del registro de campo pueden englobar: Retratos de los sujetos (incluyendo su apariencia, ropas, discursos, acciones); Reconstrucciones de diálogos (las conversaciones y los gestos, expresiones faciales); Descripción del espacio físico (a través de dibujos o descripciones del mobiliario, piso, paredes, pintura); Relatos de acontecimientos particulares (en el caso que ocurran y sean pertinentes); Descripción de las actividades (incluyendo las actitudes de los participantes); El comportamiento del observador (considerándose a si mismo, sus actitudes, sus suposiciones y todo lo que pueda afectar la colecta de los datos); para la posterior Parte Reflexiva de los Registros de Campo: Reflexiones sobre el método; Reflexiones sobre 


\section{conflictos y dilemas éticos; Reflexiones sobre el punto de vista del observador y Puntos de aclaración.}

Los diarios de campo fueron sometidos al análisis de contenido temático, en el cual, según Gomes (2011), se realiza un proceso de categorización en el sentido de establecer clasificaciones agrupando elementos, ideas o expresiones, cuyo eje central es el tema. Además, el autor sostiene que la categorización puede ser realizada previamente o surgir a partir del análisis del material de investigación, siendo este último el procedimiento adoptado en el presente trabajo.

\section{ANÁLISIS DE LOS DATOS}

Después de lecturas y relecturas de los diarios de campo, como también de la clasificación y agrupamiento de los elementos presentes, emergieron cuatro categorías: A) Conocimientos Técnicos Específicos, B) Ciclo-Empatía, C) Negociación y D) Fenomenología del Entorno, las que son descritas a continuación.

\section{A) Conocimientos Técnicos Específicos}

Esta categoría reúne los procesos educativos relacionados con aprendizajes de conocimientos técnicos específicos en la práctica del cicloturismo. Tales conocimientos emergen en gran parte de la necesidad de respuesta de los cicloturistas al aventurarse por áreas poco conocidas, la necesidad de mantención y reparo de las bicicletas, como también de su conducción; sufre gran influencia del terreno y del clima, incluyendo, por lo tanto, la necesidad de nuevas informaciones, destrezas y cuidados que se desprenden de las situaciones contingentes y vivencias cotidianas de los/as cicloturistas durante el trayecto.

De acuerdo con Duarte (2008), las personas en ambientes distintos al de su cotidianidad se aproximan a este de manera singular, y la bicicleta según uno de sus entrevistados “[...] es muy corporal. El cuerpo está siempre trabajando en comunión con la bicicleta y con el ambiente. El cuerpo es lo que da la propulsión a la bicicleta. Por causa de la irregularidad del terreno y de la dirección del viento, trabaja de forma diferente" (Duarte, 2008: 92).

Los primeros procesos educativos vivenciados por el grupo PEDAL vienen de la utilización, por primera vez, del avión en el transporte de las bicicletas, lo que incluye cuidados con la preservación del equipamiento, que incluye el desmontaje y acondicionamiento en maletas/bolsos específicos, como también, la preocupación en el proceso de carga de las mismas por parte de la empresa aérea durante el embarque.

Nos desplazamos hacia las correas por las cuales, en principio, llegarían nuestras bicicletas, sin embargo el tiempo fue pasando y no veíamos las bicicletas. Jana fue hacia uno de los funcionarios del aeropuerto para preguntar al respecto. En eso, él le informó que las bicicletas serían entregadas a través de una de las puertas que separan el espacio de retiro de equipaje del sector de carga del aeropuerto, debido a que el tamaño de las bicicletas no pasaban fácilmente por la escotilla, ni en la propia correa del equipaje, y el personal estaba preocupado de no causar daño alguno (Diario de Campo 1).

El transporte de la bicicleta por avión demanda conocimientos técnicos para el desmontaje y montaje de los diversos componentes de la bicicleta, y también cuidados con la calibración de la presión de los neumáticos y las suspensiones que funcionan con 
aire. Estos aspectos, incluso repercuten en cuestiones de planificación, pues debe ser considerado en la organización del cicloviaje. Conforme al registro en el Diario: "[...] despertamos a las 6h30min y [...] salimos rumbo al puesto de combustible para calibrar los neumáticos, pues con el transporte de las bicicletas por avión, se requiere desmontarlas y desinflar los neumáticos, pues si están con aire podrían reventarse al ser transportados en el compartimiento de carga, sin presurización" (Diario de Campo 3).

Por otra parte, y aunque el grupo posee cierta experiencia en el desplazamiento en bicicleta, este viaje proporcionó diversos aprendizajes sobre la conducción de la bicicleta, pues los participantes experimentaron diferentes tipos de terrenos y condiciones climáticas bastante distintas de lo habitual, con mucho calor, viento y poca lluvia. En este sentido, el siguiente párrafo del Diario de Campo especifica: "El día amaneció ya bien caliente, aunque había presencia de nubes, lo que atenuaba un poco la radiación solar y disminuía la sensación térmica. Utilizamos rutas con suelo de piedra del tipo pizarra, como también suelo con piedra tosca" (Diario de Campo 4).

Dentro de los aprendizajes del grupo se destaca lo relacionado con los movimientos de la marea, por ser inédita la experiencia de pedalear por la playa en un cicloviaje. Fue fundamental, en este sentido, el auxilio de los habitantes locales, tanto en la compresión del fenómeno, como para planificar los próximos trechos del trayecto.

Luiz, Spina y Edson conversaron con el guía sobre los caminos cercanos que llevan a Paracuru, él dijo que podríamos ir por la rambla del mar si tomábanos la hora de la marea baja, pues de esa forma viajaríamos sobre la arena mojada y rígida. Por lo tanto, precisaríamos consultar la tabla de las mareas, dado que cambian diariamente. Otra posibilidad sería seguir por la carretera CE 085[...]. También dice que el camino por la carretera era más largo, dijo, también, que era el único posible de recorrer en bicicleta fuera del horario de marea baja (Diario de Campo 3).

Dichos conocimientos fueron fundamentales en los momentos de planificación y de decisión del grupo sobre los caminos a recorrer durante el cicloviaje, como es posible observar en la descripción: "Spina, Gabriel, Jana y Livia pasaron antes por un puesto de internet para consultar la tabla de las mareas de la región, tomando una foto de la citada tabla desde la pantalla del computador para poder consultarla durante el trayecto" (Diario de Campo 3).

La experiencia de pedalear en arena de playa también fue bastante significativa para los miembros del PEDAL, y conocer el movimiento de las mareas fue fundamental para que tuviera lugar dicha experiencia, pues en un primer momento: “[...] intentamos pedalear un poco por la orilla de la playa, aunque la arena estaba muy blanda y sólo pudimos acarrear la bicicleta hacia el trecho de una empresa local, subiendo con las bicicletas por un barranco" (Diario de Campo 5). Ya en otro momento de ese mismo día: “[...] Spina intentó nuevamente entrar con la bicicleta a la playa y pedalear por la orilla. Esta vez la marea estaba baja, permitiendo pedalear en la arena húmeda y compacta (Diario de Campo 5).

Las condiciones del mar y el viento proporcionaron al grupo experiencias sorprendentes, como podemos observar en el fragmento siguiente:

Comenzamos a pedalear en dirección a Playa de la Baleia por la rambla del mar, donde la arena húmeda y rígida permitía un desplazamiento rápido, casi como en el asfalto. El viento a nuestro favor permitía pedalear más rápido, e incluso, en ciertos momentos, en el plano, y dada la fuerza del viento, éramos llevados por éste con una fuerza extraordinaria (Diario de Campo 7). 
Los trechos pantanosos y de lodo también fueron una novedad para el grupo, mostrando la necesidad de acarrear la bicicleta en varios momentos, tener cuidado con el barro, ante la posibilidad constante de presencia de espinas y puntas de raíces, típicas de las regiones pantanosas, al igual que con hoyos en los charcos y pozas al momento de atravesarlas montado en la bicicleta. Otro aprendizaje en la conducción de la bicicleta emergió de la experiencia con jeeperos y buggeros que informaban la necesidad de disminuir la presión de los neumáticos en terrenos arenosos, que tuvo su correlato en la experiencia posterior de viajar por senderos arenosos muy extensos. En particular, uno de los miembros vivenció con mayor rapidez y profundidad el aprendizaje de dicha técnica: "Spina sugirió disminuir bastante la presión de los neumáticos, pues él ya lo había hecho en su bicicleta, por los cual se hundía menos en la arena, mejorando, por otro lado, el desplazamiento" (Diario de Campo 17).

Otro aprendizaje del grupo se produce a raíz de la necesidad de mayor cuidado con la mantención de las bicicletas, pues el desplazamiento por la playa genera corrosión de los componentes metálicos, dado el contacto con agua salada, principalmente en la transmisión, la cual debía ser lavada y lubricada al finalizar los trayectos con tales características. En este sentido, emergió la necesidad de llevar algunas piezas de reposición para las bicicletas, principalmente en el caso de modelos más nuevos, como las de aro 29, pues hasta entonces, acostumbrados a viajar por la región sudeste, no se llevaban piezas de reposición, considerando que era posible encontrar muchos talleres de bicicletas en el camino, asunto que no ocurrió esta vez.

\section{B) Ciclo-Empatía}

La empatía fue una experiencia bastante recurrente en los diarios de campo del grupo, indicando que la bicicleta como medio de transporte en un cicloviaje potencia las relaciones empáticas, expresadas en una profundización de la comunicación, preocupación por el grupo, actitudes solidarias, entre otros aspectos. Duarte (2008), en su estudio con cicloturistas, reveló que la situación de vulnerabilidad y de exposición a factores tales como frío, hambre, cansancio y sed, producto de la opción de transportarse en bicicleta, es percibida por las personas en el camino y, normalmente, se muestran curiosas, solícitas y dispuestas a interactuar e incluso ayudar a los viajaros. Según el mismo autor, la curiosidad y la receptividad proporcionada por la bicicleta favorece considerablemente la relación entre cicloturistas y los habitantes locales durante los trayectos.

La relación entre los cicloturistas también fue abordada por Duarte (2008), quien menciona que las experiencias en los viajes son enriquecidas por la vivencia compartida con otras personas, proporcionando momentos de diversión, de dificultades de relación y de solidaridad en la superación de los problemas y, por tanto, de fortalecimiento de las amistades.

Diversas fueron las situaciones de auxilio de los habitantes locales para con los cicloturistas y también entre las personas del mismo grupo. No obstante, seleccionamos una en que aquello se muestra durante el auxilio a una de las integrantes de PEDAL, quien sufrió una fuerte intoxicación:

Livia no se sentía bien y venía más atrás junto a Spina, luego al término del pantano había un sendero estrecho de arena muy blanda que no permitía pedalear. [...] Livia, debilitada, paró de acarrear su bicicleta y Spina y Edson se alternaban el acarreo de sus bicicletas y la de ella, de esa forma ella lograba mantenerse caminando, aunque con un ritmo más lento, pues además 
estaba con algo de fiebre. Bajo la sombra de un conjunto de árboles, Luiz, Denise y Sueli descansaban esperando a Edson, Spina y Livia. Cuando llegaron, hicieron un suero casero con dos pequeños saches, uno de sal y uno de azúcar que Edson había guardado. Sueli descascaró una manzana y fue cortando pequeños pedazos que daba a Livia [...]. Luiz llevó la bicicleta de Livia mientras Spina y Edson descansaban un poco, después retornó, informó que Gabriel y Jana habian continuado y que donde había dejado la bicicleta de Livia ya era posible pedalear. [...] Después de aproximadamente $3 \mathrm{~km}$ de mucha dificultad, desde el cruce en balsa, llegamos al poblado de Patos. [...] Luiz se dirigió hacia una de las pocas casas del poblado y conversó con la señora que lo atendió, describiendo sucintamente la situación de la compañera del grupo que se encontraba mal. [...] Conversamos un poco con el matrimonio y sus hijos, solicitamos algunas informaciones sobre el camino y nos despedimos haciendo una pequeña contribución en dinero, cerca de $R \$ 10,00$, los cuales fueron rechazados en un primer momento por la señora, pues según ella, sólo realizó lo que debería ser hecho [...], pero con nuestra insistencia [...] de que era una pequeña contraparte, ella aceptó, también agradeciendo (Diario de Campo 8).

La empatía también se manifestó entre el grupo PEDAL y otros cicloturistas con los cuales se tuvo contacto por el camino. Un ejemplo fue expresado frente a la dificultad de encontrar piezas de recambio para una de las bicicletas. Asunto resuelto al encontrar una pareja de cicloturistas, como se describe en el Diario: "Jana conversando con otro cicloturista, el cual estaba con una bicicleta aro 29 como la de ella, comentó sobre el rayo quebrado y la dificultad para conseguir otro, a lo que él dice tener algunos de reserva y por lo tanto le dio uno" (Diario de Campo 15).

El cansancio o las propias averías de la bicicleta mantuvieron, muchas veces, a alguien del grupo con un ritmo más lento. En momentos como esos, la empatía, a través de gestos de solidariedad, también se hizo presente en la relación del grupo. Concretamente, algunos continuaban sin problemas pero esperaban a los restantes haciendo paradas constantes para huir del sol, y otros miembros, en mejores condiciones, acompañaban a quienes estaban más atrás, como podemos observar a continuación: “[...] Sueli se mostraba más cansada y quedó un poco atrás, dijo que la arena estaba pesada para ella aquel día. Edson se quedó acompañando y pedaleando al ritmo de ella" (Diario de Campo 12).

Esta categoría refleja la empatía, manifestada fundamentalmente en la solidaridad, como uno de los elementos garantizadores de seguridad, el apoyo expreso durante el viaje, la comunicación del grupo, tanto entre personas casuales o internas, reafirmando la confianza en el otro, lo que posibilita, en un contexto de cultura automovilística hegemónica, realizar viajes en un medio de transporte tan vulnerable. El viajar en bicicleta antes de ser un ejercicio físico, es un ejercicio permanente de humildad individual $\mathrm{y}$, al mismo tiempo, de resonancia social, pues si bien proporciona libertad, vivenciada en cada kilómetro, tal libertad se sustenta en una constante relación de dependencia con el semejante.

\section{C) Negociación}

Esta categoría en cuestión se constituye por las situaciones de decisión colectiva del grupo, tales como la determinación de la ciudad de parada y el trayecto, la elección de establecimientos para alimentarse o el hospedaje, la contratación eventual de paseos turísticos, y las negociaciones con las personas locales sobre condiciones y costos de los servicios a cancelar.

Las averiguaciones de precios y condiciones estuvieron presentes en casi todos los diarios de campo, pues encontrar hospedaje fue una tarea de cada día y el grupo se organizó 
de manera de llevar a cabo tal proceso lo más rápido posible a fin de garantizar un costo accesible, condiciones mínimas de confort, higiene y seguridad para el descanso. Esto también ocurrió para el lavado de ropas personales o la revisión periódica y la seguridad de las bicicletas.

Nos dividimos en grupos y fuimos a averiguar precios y condiciones de hospedaje. Luiz y Edson volvieron con la mejor propuesta, cuatro cuartos con baño interno, ventilador y costo de $R \$ 20,00$ por persona. Pidieron a Denise, Livia y Sueli evaluar los cuartos, quienes los aprobaron (Diario de Campo 5).

Las negociaciones respecto a los paseos también fueron frecuentes, pues en aquella región muchos paseos son inviables en bicicleta. De manera que, para conocer puntos turísticos en regiones de dunas, pantanos, ríos y lagunas era preciso alquilar barcos, buggies, camionetas o, en algunos casos, vehículos con tracción 4x4.

Decidimos hacer el paseo, pero una parte del grupo estaba indecisa si pernoctar en el lugar o seguir hasta la próxima ciudad. El guía también indicó un hostal. Livia y Spina fueron hasta allá para verificar los precios. Luiz y Edson negociaron con dos buggeros, que cobraban $R \$ 150,00$ por buggy. Consiguieron arrendar por $R \$ 140,00$ cada buggy. Livia y Spina retornaron con la información del hostal que contemplaba cuartos cuádruples por $R \$ 40,00$ con desayuno. Surgieron dos propuestas: una de hacer el paseo, almorzar, descansar un poco y continuar en viaje hasta la próxima ciudad, y la otra era dormir en el hostal y seguir al otro día por la mañana. Puesta a votación, ganó la segunda opción (Diario de Campo 3).

Las decisiones colectivas del grupo fueron constantes y, en varias ocasiones, la argumentación y la votación fueron las estrategias utilizadas para la resolución final, como fue el caso de la conversación durante el paseo en barco al Delta do Parnaíba:

[...] teníamos la opción de retornar a la carretera y continuar pedaleando en el asfalto hasta Araioses, en Maranhão, lo que sería un camino más largo, o seguir desde la ciudad de Parnaíba (PI) hasta Araioses en barco, recordando que en caso de optar por la última alternativa sería necesario conversar con los tripulantes del barco [...] para verificar el valor y la viabilidad [...]. Fur realizada [...] la votación [...], y ganó la opción de seguir en barco (Diario de Campo 16).

La constante exigencia de negociar, el cansancio provocado por algunas situaciones adversas ocurridas y la intensa convivencia diaria con personas con diferentes personalidades, aunque hayan sido compañeras en otros cicloviajes y en otros contextos, también genera tensiones, conforme podemos percibir en la escena descrita a continuación:

[...] Gabriel pide esperar para comprar agua, después continuamos hasta el hostal. [...] Livia comenta en general, que Gabriel tiene una verdadera desesperación por quedar sin agua. En eso, él, irritado y con tono de voz más alto, responde que suda mucho y que realmente necesita agua! Edson comentó: tranquilo Gabriel! Cambiamos entonces el foco de conversación hacia la decisión sobre el hospedaje. El precio nos pareció adecuado, aunque percibimos que el hostal aún no estaba terminado [...]. Otro inconveniente fue que sólo había dos cuartos con camas matrimoniales y en el grupo había tres parejas. Denise propuso realizar un sorteo entre las parejas para resolver la situación. Livia, irritada, dice que el día de ayer ya se quedó con Spina en el box de la cama matrimonial sin colchón y que hoy no se quedará otra vez, agrega que 
tampoco va a participar del sorteo porque siempre pierde. Sueli dijo que no se incomodaba, y que las demás parejas podían dormir juntos, aunque el marido de ella dijo que él también había compartido la habitación con otra pareja la noche anterior y que, por tanto, quería una habitación con cama matrimonial separada (Diario de Campo 18).

\section{D) Fenomenología del entorno}

Es importante resaltar que la denominación atribuida a esta categoría pretende aludir a concepciones que resalten la experiencia del entorno, desde una visión compleja y sistémica, distante por lo tanto de aquellas concepciones preservacionistas y/o conservacionistas del medio ambiente que, de acuerdo con Rodrigues y Gonçalves Junior, están orientadas a la “[...] conservación/preservación de una naturaleza distante, que desconsidera el medio urbano, así como del propio cuerpo, como parte no menos importante de esa naturaleza, contribuyendo al distanciamiento de las relaciones ser humano-medio ambiente" (Rodrigues y Gonçalves Junior 2009: 989). Por lo cual, se entiende esto como un acoplamiento estructural (Maturana y Varela, 1986) y configurador de lo que denominamos individuo/entorno. En términos específicos, las percepciones del entorno descritas en esta categoría contemplan, además de las bellezas naturales de la región, la devastación, las áreas urbanas, las personas, los aspectos históricos, culturales y sociales. Es decir, se intenta una aproximación estética, ética y política desde la experiencia situada en el trayecto.

Por estar viajando en bicicleta, en muchos momentos tuvimos que decidir si conocer los puntos turísticos de la ciudad desplazándonos en bicicleta o en transporte público, o incluso caminando. Tales desplazamientos nos permitieron conocer diversos puntos que no eran destinos turísticos comunes. Esto permitió la observación de los contrastes actuales, y la percepción de la violencia, pobreza y contaminación en las zonas marginales próximas a los puntos turísticos, incluso los más conocidos.

En el trayecto hasta la Playa de Iracema, punto poco frecuentado por los turistas, el grupo constató que se encontraba “'[...] un poco contaminado, muchas botellas desechables y envases de aluminio esparcidos por el terreno, y una especie de casi abandono, además de muchos restos de embarcaciones. Jana incluso comentó que la escena le recordaba un extracto del libro 'Capitanes de Arena', de Jorge Amado" (Diario de Campo 2).

En el trayecto realizado en bus, el transporte recomendado por la recepcionista del hostal debido a su mayor seguridad, hasta un famoso punto turístico de Fortaleza, registramos la siguiente nota de campo:

En el ómnibus conversamos con dos jóvenes que, vestidos con ropas simples y apariencia descolorida y de bastante uso, [...] nos comentaron sobre la Playa del Futuro, indicando que era una de las más bonitas de esa región, posteriormente se despidieron descendiendo del ómnibus en un parada de una comunidad bastante empobrecida. Después de aproximadamente cinco minutos, descendimos del ómnibus justo en frente a Crocobeach. El lugar contaba con una gran infraestructura de bares y restaurantes orientados, fundamentalmente, al servicio de los turistas (Diario de Campo 2).

Durante los trayectos en bicicleta, el grupo podía observar las condiciones de vida de las comunidades que habitan zonas distantes de los puntos turísticos. Fundamentalmente, eran poblados bastante humildes y acogedores, a quienes les llamaba la atención el grupo, preguntando muchas veces de dónde veníamos y hacia qué lugar nos dirigíamos (Diario de Campo 4). 
Por otra parte, en algunos casos el grupo quedaba prácticamente sin opciones de establecimientos para alimentarse y alojar, como fue el caso en una de las ciudades que no era lugar de visita turística, y en la cual el único hotel indicado por los habitantes no ofrecía condiciones mínimas de confort ni de seguridad, al punto de preferir acampar en algún lugar del camino, en caso de no encontrar otra opción. En la misma ocasión, las opciones de alimentación fueron bastante limitadas.

[...] el grupo no quiso quedarse [en el hotel] y se dirigió a la calle en la dirección de Piauí, pues recibió noticias de que allá había un hotel con restaurante. La información era equivocada [...]. Nos devolvimos un poco y nos detuvimos en un pequeño restaurante [...] que estaba en funcionamiento. Al solicitar el servicio, para lavarnos las manos, fuimos llevados a la cocina y nos percatamos de que el local era una residencia bastante pobre y había una señora anciana sentada en el corredor con aparente dificultad de locomoción y posiblemente con alguna enfermedad (Diario de Campo 14).

Las conversaciones con los habitantes durante el cicloviaje, en los momentos de descanso o durante la estadía en las ciudades y poblados, fueron fundamentales para tener a lo menos una comprensión básica del contexto cultural y social de las comunidades por las cuales PEDAL transitó. Como ejemplo, citamos la conversación con algunos niños y niñas en el momento en que el grupo descansaba al lado de una escuela:

Denise comenzó a conversar con un niño sobre la escuela, él le dijo que ya había estudiado allí [...] En medio de la conversación, abrió un caramelo y arrojó el papel al suelo. Ella se levantó y tomó el papel diciendo que no era bueno arrojar basura ahí, pues estaba dejando su ciudad fea y sucia, además de dañar la naturaleza, pues cerca de allí había un río muy bonito, pero que con la suciedad se podría ahogar y,... al hacer una pausa... él mismo completó "...morir”. El también dijo que "Nunca nadie le habló así". Ella tomó también una bolsa de plástico que estaba cerca y se dirigió a la calle para dejar la basura en algún basurero, sin embargo no había uno cerca. Entonces, se dirigió al restaurante que estaba en frente, y nada! Percibió que el problema era muy complejo, uno de los empleados del restaurante llevó la basura adentro de la residencia. Al volver, ella fue a lavarse las manos en un grifo dentro del patio de la escuela, pero no había agua. El niño mencionó que siempre faltaba agua en la escuela y que viene un camión cisterna a abastecerla (Diario de Campo 14).

Otro ejemplo, muy significativo de las conversaciones con los habitantes locales, surgió del diálogo con otro niño en un refectorio, en el momento en que el grupo tomaba una merienda y se le invitó a compartir el alimento:

[...] Gabriel le preguntó la edad y dijo tener 11 años. Luiz le preguntó en qué año escolar estaba y él respondió que en tercero, pues había repetido varias veces. Contó además que no le gustaba estudiar ni ir a la escuela. [...] Al niño le causaba curiosidad la camiseta del grupo, por el diseño y la inscripción, y preguntó de qué trataba. Luiz le pidió que leyera y se dio cuenta que el niño apenas reaccionaba y que, con mucha dificultad, consiguió leer PEDAL, pero no el detalle de la sigla, pues era muy largo (Diario de Campo 5).

La percepción de las bellezas naturales también fue bastante significativa para el grupo y, por eso, trechos como el que se presenta a continuación, tuvieron bastante realce en los diarios de campo. 
Pasamos por la Playa de Tatajuba. En el camino transitamos por varias localidades con piscinas naturales, con aguas cristalinas, transparentes y de un cierto tono verde. Denise, Sueli y Jana dijeron haber quedado impresionadas por la belleza. Spina, por otra parte, agregó que si pudiese, en el caso de que fuese agua dulce, entraría en el agua (Diario de Campo 12).

\section{CONCLUSIONES}

[...] lo real no está ni en la salida ni en la llegada: lo que se dispone para nosotros está en el medio de la travesía (Rosa, 1994: 85).

El poema de Guimarães Rosa abre estas conclusiones para indicar lo que percibimos respecto al objetivo de identificar y analizar los procesos educativos vivenciados en el contexto de un cicloviaje.

El análisis de los datos permitió identificar procesos educativos vivenciados por el grupo de cicloturistas relacionados con conocimientos de orden técnico, el uso de la bicicleta y la planificación de los cicloviajes, como también con aspectos geográficos, climáticos, el movimiento de las mareas, entre otros, muchos de los cuales fueron posibles sólo a partir del saber de las comunidades locales.

Los datos también develaron actitudes de empatía entre los miembros del grupo durante el cicloviaje y entre las personas que habitaban los lugares recorridos por el PEDAL. Las frecuentes situaciones de vulnerabilidad, en cierta medida, provocaron fuertes relaciones de interdependencia entre los miembros del grupo, favoreciendo actitudes de solidaridad y que, al mismo tiempo, desencadenaban en habitantes locales tal emoción para con el grupo.

Además de esto, la exposición del cicloturista (incluyendo la mencionada vulnerabilidad) posibilita una experiencia más sensible y directa con el entorno, y en consecuencia consigo mismo. Normalmente, en una situación de viaje en vehículo motorizado (en el que la rapidez del automóvil es bastante superior a la de la bicicleta, por el uso de vías preferentemente asfaltadas y expresas, o en el caso de vehículos cerrados con aire acondicionado y vidrios polarizados), a los viajeros se les hace más difícil percibir las condiciones climáticas, las de contaminación, las poblaciones empobrecidas que viven en los márgenes de las regiones turísticas, las variaciones de ritmo en el propio pedalear, la orientación e intensidad del viento, el sudor y el esfuerzo, entre otros.

La negociación emergió como inherente a las relaciones con el mercado de servicios, principalmente, en los centros turísticos, en los cuales la alta rotación y circulación de turistas encarece el hospedaje, la alimentación y los demás servicios. Otro aspecto a ser considerado, es la relación de convivencia que incluye negociaciones en la toma de decisiones o la mediación de conflictos en busca de una solución que atienda y sea pertinente al colectivo.

De acuerdo a las categorías aquí presentadas, al igual que Schetino (2005), consideramos al cicloturismo "[...] como posibilidad de una vivencia crítica y creativa de ocio" (Schetino 2005: 192). Y frente a esto, entendemos que la percepción promovida por la utilización de la bicicleta puede favorecer procesos de acción educativa, tanto formal como no formal, escolar y no escolar, en base a un ocio crítico y ambiental, pues posibilita la sensibilización de las personas respecto a sí mismos, sus semejantes y el entorno, en las dimensiones biológicas, sociales, éticas y políticas. En este sentido, aquello se vincula a la relación de 
lo experimentado en los cicloviajes, "[...] el uso de la bicicleta, presente en el cotidiano de muchas personas, acaso concretamente en la vida adulta al menos en los recuerdos de infancia, con asuntos importantes de ser abordados en la contemporaneidad, tales como el ocio y la educación ambiental" (Gonçalves Junior et. al., 2011: 14).

De igual forma, los procesos psicológicos y sociales que se desenvuelven en este tipo de actividades tienen la potencialidad y la exigencia de ser resueltos por los mismos participantes, su involucramiento y participación dando sentido y viabilidad al proceso al y resultado. Tales aspectos nos llevan a entender que los aprendizajes desarrollados confluyen hacia una mayor conciencia de la propia acción tanto sobre sí mismo como sobre el entorno, dos aspiraciones de cualquier modelo educativo actual, en los distintos ámbitos de la existencia de las personas involucradas.

\section{REFERENCIAS BIBLIOGRÁFICAS}

Bogdan, R. y Biklen, S. (1994). Investigação qualitativa em educação: uma introdução à teoria e aos métodos. Porto: Porto Editora.

Brandão, C. (2002). A educação como cultura. Campinas: Mercado de Letras.

Byrne, D. (2010). Diarios de bicicleta. Buenos Aires: Editorial Mondadori.

Duarte, J. (2008). Cicloturistas e suas percepções ambientais: um estudo na Estrada Real. Dissertação (Mestrado em Turismo e Meio Ambiente). Belo Horizonte: Centro Universitário UNA.

Fiori, E. (1986). Conscientização e educação. Educação e Realidade, v. 11, n. 1, 3-10.

Freire, P. (2005a). Pedagogia do oprimido. 43 ed. Rio de Janeiro: Paz e Terra.

Freire, P. (2005b). Pedagogia da esperança: um reencontro com a pedagogia do oprimido. 12 ed. Rio de Janeiro: Paz e Terra.

Gomes, R. (2011). A análise de dados em pesquisa qualitativa. En M. Minayo (Ed.), Pesquisa social: teoria, método e criatividade (pp.79-108). Petrópolis: Vozes.

Gonçalves Junior, L.; Carmo; C. S.; Colloca, E. A. y Corrêa, D. A. (2011). Projeto de educação ambiental e lazer (PEDAL): dialogando a partir do cicloturismo na escola. Licere. v. 14, n. 4, $1-16$.

Gonçalves Junior, L. (2014). Edital de atividades de extensão - Projeto de educação ambiental e lazer consciente (PEDAL-Consciente). São Carlos: ProEx/UFSCar.

Maturana, H. y Varela, F. (1986). El árbol del conocimiento. Santiago de Chile: Editorial Universitaria.

Oliveira, M.; Silva, P.; Gonçalves Junior, L.; Montrone, A. y Joly, I. (2009). Processos educativos em práticas sociais: reflexões teóricas e metodológicas sobre pesquisa educacional em espaços sociais. En Anais da 32 $2^{a}$ Reunião Anual da Associação de Pós-Graduação e Pesquisa em Educação. Caxambu: ANPEd.

Rodrigues, C. y Gonçalves Junior, L. (2009). Ecomotricidade: sinergia entre educação ambiental, motricidade humana e pedagogia dialógica. Motriz, v.15, n.4, 987-995.

Roldan, T. (2000). Cicloturismo: planejamento e treinamento. Monografia (Graduação em Educação Física). Campinas: UNICAMP.

Rota das Emoções. (2013). A rota. Disponible en: <http://www.rotadasemocoes.com.br/a-rota.html>. Acceso en: 10 mai. 2013.

Rosa, G. (1994). Grande sertão: veredas. En G. Rosa (Ed.). Ficção completa em dois volumes. v. 2 (pp. 2-875). Rio de Janeiro: Nova Aguilar.

Schetino, A. (2006). Cicloturismo como vivência crítica e criativa de lazer. Monografia (Especialização em Lazer). Belo Horizonte: UFMG.

Schetino, A. (2005). Cicloturismo e lazer: ampliando o olhar sobre as viagens de bicicleta. En XVII Encontro Nacional de Recreação e Lazer. Campo Grande: ENAREL. 
Sérgio, M. (1999) A racionalidade epistémica na educação física do século XX. En M. Sérgio; R. Trovão; A. Feitosa; F. Almada y V. Tavares (Ed.), O sentido e a acção (pp.11-30). Lisboa: Instituto Piaget.

Toro, S. y Lührs, O. (2012). La Universidad Austral de Chile, entre el reaccionar y el accionar, una mirada desde la Ecomotricidad. En Pavesi, A. Et. Al. Visiones y experiências Ibero-americanas de sostenibilidad en las universidades (pp.179-186). Madrid: USP, UAM Ediciones. 
